\title{
EFEITO DO TEOR DE SÓLIDOS E DA CONCENTRAÇÃO DE SACAROSE NA ACIDIFICAÇÃO, FIRMEZA E VIABILIDADE DE BACTÉRIAS DO IOGURTE E PROBIÓTICAS EM LEITE FERMENTADO ${ }^{1}$
}

\author{
Maricê N. OLIVEIRA ${ }^{2, *}$, M. Regina DAMIN ${ }^{3}$
}

\section{RESUMO}

Doze lotes de leites fermentados foram preparados a $42^{\circ} \mathrm{C}$ nos quais as variáveis estudadas foram o teor de sólidos totais (12 e $15 \%$ ), o teor de sacarose (0\% e 8\%) e o tipo de co-cultura (Streptococcus thermophilus e Lactobacillus delbrueckii subsp. bulgaricus ; Streptococcus thermophilus e Lactobacillus acidophilus ; Streptococcus thermophilus e Lactobacillus rhamnosus). Parâmetros cinéticos para a diminuição do $\mathrm{pH}$ até 4,5 foram calculados. Determinações físico-químicas e microbiológicas foram realizadas após um e sete dias de armazenamento dos produtos a $4^{\circ} \mathrm{C}$. Com o aumento do teor de sólidos totais e adição de sacarose, a atividade de água do leite diminuiu e o tempo para atingir pH 4,5 variou conforme a co-cultura empregada. Os leites fermentados por S. thermophilus e L. acidphilus (STLA) apresentaram pós-acidificação mais acentuada. Aqueles fermentados por S. thermophilus e L. rhamnosus (STLR) foram mais estáveis. Os leites contendo maiores teores de sólidos totais foram aqueles com maior acidez total independente da co-cultura usada. Com o aumento do teor de sacarose e de sólidos solúveis houve um aumento da firmeza usando-se as co-culturas STLR e STLA. Após sete dias, o número de bactérias do iogurte e as probióticas não variou significativamente. Em todos os lotes, o número de bactérias probióticas ficou acima do sugerido pela literatura.

Palavras-chave: iogurte; probióticos; acidificação; viabilidade.

\section{SUMMARY}

EFFECT OF TOTAL SOLIDS AND SUCROSE CONTENTS ON ACIDITY, FIRMNESS AND VIABILITY OF YOGURT AND PROBIOTIC BACTERIA IN FERMENTED MILK. Twelve batches of fermented milk were prepared at $42^{\circ} \mathrm{C}$ where the studied variables were total solids content (12 and 15\%), sucrose concentration (0 and 8\%), and co-culture type (Streptococcus thermophilus and Lactobacillus delbrueckii subsp. bulgaricus ; Streptococcus thermophilus and Lactobacillus acidophilus ; Streptococcus thermophilus and Lactobacillus rhamnosus. Kinetic parameters to decrease $\mathrm{pH}$ until 4.5 were calculated. Physico-chemical and microbiological determinations were carried out on products after 1 and 7 days of storage at $4^{\circ} \mathrm{C}$. The increase in total solids and the addition of sucrose resulted in water activity decrease, which affected the time to reach pH 4.5 according to the milk and co-culture employed. The milk fermented by Streptococcus thermophilus and Lactobacillus acidophilus (STLA) presented higher post acidification. Besides, the milk fermented by Streptococcus thermophilus and Lactobacillus rhamnosus (STLR) was the more stable. The milks containing higher levels of total solids reached higher acidity independently of the co-culture. Increasing sucrose amounts and total solids of milk resulted in higher firmness using the co-cultures STLR e STLA. After seven days of storage, there were no major differences in the initial counts of yogurt and probiotic bacteria in all fermented milks. In all batches, the number of probiotic bacteria was higher than suggested by literature.

Keywords: yogurt; probiotics; acidification; viability.

\section{1 - INTRODUÇÃO}

Muitos beneficios para a saúde têm sido relacionados ao consumo de organismos probióticos $[16,17,22]$. Em geral, dependendo da cepa empregada e do efeito benéfico desejado, um consumo de bactérias probióticas entre $10^{8}$ e $10^{11} \mathrm{CFU} /$ dia é recomendável [23].

Iogurte é um leite fermentado produzido pela adição de Lactobacillus delbrueckii subsp. bulgaricus e Streptococcus thermophilus ao leite. Lactobacillus delbrueckii subsp. bulgaricus libera aminoácidos e peptídeos da proteína do leite, estimulando o crescimento do Streptococcus thermophilus. O crescimento de Lactobacillus delbrueckii subsp. bulgaricus é estimulado pelo ácido fórmico ou $\mathrm{CO}_{2}$ liberado durante o crescimento de Streptococcus thermophilus. Ocorre uma relação simbiótica [1, 24].

${ }^{1}$ Recebido para publicação em 03/10/2002. Aceito para publicação em 15/07/2003 (000997)

2 Depto. de Tecnologia Bioquímico-Farmacêutica, Faculdade de Ciências Farmacêuticas, Universidade de São Paulo, Av. Prof. Lineu Prestes, 580, Bl 16. CEP - 05508-900. São Paulo, Brasil. E-mail: monolive@usp.br. Faculdade de Ciências Farmacêuticas, Universidade de São Paulo * A quem a correspondência deve ser enviada.
A matriz de um processo de fermentação láctica destinada, seja à produção de um fermento, seja à fabricação de um produto, passa necessariamente pela colocação em marcha das condições de cultura dos meios adaptados às cepas bacterianas implicadas. Por outro lado, o estudo da influência das condições de cultura sobre as cinéticas de crescimento e de acidificação e, sobre os rendimentos da produção (em biomassa ou em ácido láctico) permitem a obtenção de informações interessantes sobre a fisiologia de cepas bacterianas utilizadas industrialmente. Dentre estas condições, a temperatura, o valor de $\mathrm{pH}$ e as concentrações em substrato e em produtos, são aquelas que agem mais sobre a fase de crescimento exponencial das bactérias lácticas $[1,24]$. As características do inóculo, a atividade de água (Aa), a osmolalidade, as concentrações de oxigênio e de substâncias inibitórias do meio são fatores importantes. Portanto é interessante conhecer seus efeitos sobre a cinética de crescimento e de acidificação.

As bactérias probióticas crescem lentamente no leite devido a falta de atividade proteolitica [7], e a prática mais comum é a de adicionar as bactérias do iogurte para melhorar o processo de fermentação para a fabricação de leites fermentados contendo probióticos [3, 11, 15, 18]. Entretanto, Lactobacillus delbrueckii subsp. 
bulgaricus produz ácido láctico durante o armazenamento sob refrigeração. Este fenômeno conhecido por pósacidificação, afeta a viabilidade das bactérias probióticas. Para superar o problema da pós-acidificação, a tendência atual é a de usar culturas iniciadoras isentas de Lactobacillus delbrueckii subsp. bulgaricus [3].

A firmeza do iogurte é um atributo importante na aceitação do produto pelo consumidor. Segundo ROSSI [13] E O`NEIL, KLEYN \& HARE [10], o iogurte deve ter textura suave e corpo viscoso e não apresentar fissuras; ser firme e coeso para ser consumido com colher.

Diversos fatores afetam a viabilidade de bactérias probióticas em leite fermentado [4, 8]. Altas concentrações de sacarose adicionadas ao leite antes da fermentação podem inibir as bactérias do iogurte levando a longos tempos de fermentação e a um baixo desenvolvimento de acidez [20]. Isto se deve aos efeitos osmóticos dos solutos no leite e à baixa atividade de água [21, 23]. GARDINI et al. [5] demonstraram que a composição do produto em termos de conteúdo de sólidos totais afeta a viabilidade dos probióticos. SHAH, ALI \& RAVULA [19] demonstraram que as bactérias probióticas têm baixa viabilidade em produtos fermentados.

O presente trabalho teve como objetivos verificar a influência da adição de sacarose e do aumento do teor de sólidos do leite na acidificação, firmeza e viabilidade de bactérias do iogurte e probióticas em leite fermentado.

\section{2 - MATERIAL E MÉTODOS}

\section{1 - Fabricação do leite fermentado}

Utilizou-se leite integral pasteurizado da marca Top (Paulista, Brasil) normal e padronizado com leite em pó desnatado (Glória, Rio de Janeiro) em 15\% de sólidos totais e $26 \mathrm{~g} / \mathrm{L}$ de gordura. O leite foi repartido em frascos de $250 \mathrm{~mL}$. A seguir, acrescentou-se sacarose conforme o leite. Os leites foram assim denominados L1 (leite $12 \%$ sólidos totais $+0 \%$ de sacarose), L2 (leite $12 \%$ sólidos totais $+8 \%$ de sacarose), L3 (leite $15 \%$ sólidos totais + 0\% de sacarose) e, finalmente, L4 (leite $15 \%$ sólidos totais $+8 \%$ de sacarose).

A cultura láctea foi previamente diluída em $50 \mathrm{~mL}$ de leite esterilizado. A contagem inicial dos inóculos foi de $3,5 \times 10^{7} \mathrm{UFC} / \mathrm{mL}, 1,5 \times 10^{7} \mathrm{UFC} / \mathrm{mL}, 6,0 \times 10^{7} \mathrm{UFC} /$ $\mathrm{mL}, 5,0 \times 10^{6} \mathrm{UFC} / \mathrm{mL}$ para as culturas de ST, LB, LA e LR, respectivamente. A partir desta solução, procedeuse à inoculação do leite numa razão de 50\% (vol/vol) Streptococcus thermophilus e 50\% (vol/vol) Lactobacillus delbrueckii subsp. bulgaricus (STLB), de 50\% (vol/vol) Streptococcus thermophilus, 50\% (vol/vol) Lactobacillus acidophilus (STLA) e 50\% (vol/vol) Streptococcus thermophilus, 50\% (vol/vol) Lactobacillus rhamnosus (STLR). As seguintes culturas liofilizadas para inoculação direta foram utilizadas: ST, Streptococcus thermophilus TA040; LB, Lactobacillus bulgaricus LB340; LA, Lactobacillus acidophilus LAC4 e LR, Lactobacillus rhamnosus LBA, Rhodia, França.
Os erlenmeyrs contendo o leite foram colocados em banho-maria acoplados ao sistema CINAC (Ysebaert, Frépillon, França) até estabilização da temperatura a $42^{\circ} \mathrm{C}$. Após a inoculação, o leite adicionado de cultura láctica foi homogeneizado e a cinética de acidificação seguida pelo Sistema CINAC até valor de $\mathrm{pH}$ de 4,5. A seguir o produto foi homogeneizado manualmente com uma haste de aço inox através de movimentos suaves durante dois minutos, disposto em potes, resfriados em banho de gelo e estocados a $4^{\circ} \mathrm{C}$.

O teor de sólidos totais dos iogurtes foi determinado gravimetricamente em estufa à vácuo Marconi (Piracicaba, Brasil) a $70^{\circ} \mathrm{C}$ durante $6 \mathrm{~h}$.

\section{2 - Medida da atividade acidificante}

Cada fermentação, feita em duplicata, foi monitorada através do Sistema CINAC [2]. A partir dos dados obtidos, calcularam-se as velocidades de acidificação $(\mathrm{dpH} / \mathrm{dt})$, o tempo no qual atinge-se a velocidade máxima $\left(\mathrm{T}_{\max }, \mathrm{h}\right)$ e o tempo para atingir valor de $\mathrm{pH} 4,5\left(\mathrm{~T}_{\mathrm{pH} 4,5}, \mathrm{~min}\right)$.

\section{3 - Análises físico-químicas e microbiológicas}

A atividade de água dos iogurtes foi determinada em equipamento Novasina a $25^{\circ} \mathrm{C}$. A pós-acidificação foi determinada pela medida do valor de $\mathrm{pH}$ usando potenciômetro Quimis modelo Q-400M1 (São Paulo, Brasil). Para determinação do teor de acidez total titulável, expressa em graus Dornic, foi utilizado o método descrito pelo INSTITUTO ADOLFO LUTZ [6].

Amostras de iogurte $(1 \mathrm{~mL})$ e do inóculo foram homogeneizadas com $9 \mathrm{~mL}$ de água triptonada $0,1 \% \mathrm{p} / \mathrm{v}$ durante $2 \mathrm{~min}$ em um agitador de tubos e, em seguida, foram feitas diluições utilizando-se o mesmo diluente e inoculações em meios seletivos. L. bulgaricus, L. acidophilus e L. rhamnosus foram enumerados em MRS (Merck, São Paulo) a valor de pH 5,4 após incubação anaeróbica a $37^{\circ} \mathrm{C}$ por $72 \mathrm{~h}$. S. thermophilus foi contado em M17 (Merck, São Paulo) após incubação aeróbica a $37^{\circ} \mathrm{C}$ durante $72 \mathrm{~h}$.

A análise do perfil de textura dos leites fermentados foi feita através de teste de dupla compressão com cilindro acrílico com $2,5 \mathrm{~cm}$ de diâmetro, em analisador de textura TA-XT2 (Stable Micro Systems, Godalming, Inglaterra) controlado por microcomputador. A distância percorrida pelo cilindro na amostra foi de $10 \mathrm{~mm}$ numa velocidade de $10 \mathrm{~mm} / \mathrm{s}$. O atributo firmeza foi determinado segundo recomendações de PONS \& FISZMAN [12] que corresponde à altura do primeiro pico da curva de dupla compressão.

Todas as análises físico-químicas e microbiológicas foram feitas em duplicata após 1 e 7 dias de armazenamento do produto a $4^{\circ} \mathrm{C}$.

\section{4 - Análise estatística}

A partir dos resultados obtidos procedeu-se à Análise de Variância (ANOVA) e aplicou-se o teste de Tukey mediante programa Statistica Statsoft (Tulsa, Estados Unidos). Em todas as análises considerou-se um nivel de significância $\mathrm{p} \leq 0,05$. 


\section{3 - RESULTADOS E DISCUSSÃO}

\section{1 - Acidificação}

A Tabela 1 apresenta os teores de sólidos totais, a atividade de água e os parâmetros cinéticos de quatro diferentes leites fermentados por culturas mistas de $S$. thermophilus (ST), L. bulgaricus (LB), L. acidophilus (LA) e L. rhamnosus (LR). Observa-se que existe efeito de sólidos totais e do teor de açúcar $(\mathrm{p} \leq 0,05)$ sobre os mesmos. Na primeira fase da fermentação, verifica-se que o tipo de leite afeta Vmax e Tmax. Para a co-cultura STLB, houve diferença significativa da Vmax com o aumento do teor de sólidos e do teor de sacarose. Tmax é menor quando o leite foi padronizado em 15\% de sólidos totais e acrescido de $8 \%$ de sacarose. Usando-se a co-cultura STLA, Tmax é menor quando da incorporação de açúcar. Observa-se que Vmax dos leites fermentados por STLR foram significativamente diferentes enquanto Tmax foi afetado pelo aumento do teor de sólidos e do teor de sacarose. O menor valor de $\mathrm{V} \max \left(7,7 \times 10^{-3} \cdot \mathrm{upH} / \mathrm{min}\right)$ foi obtido usando-se STLA em leite com 12\% de sólidos totais (L1), enquanto o maior $\left(19,0 \times 10^{-3}\right.$. upH/min), emprega-se STLB em leite com $12 \%$ de sólidos totais acrescidos de $8 \%$ de sacarose (L2). O tempo (Tmax) para atingir Vmax variou de 2,6h (L2, STLR) a 6,4h (L1, STLA).

TABELA 1. Parâmetros cinéticos de quatro diferentes leites fermentados por culturas mistas de S. thermophilus (ST), L. bulgaricus (LB), L. acidophilus (LA) e L. rhamnosus (LR).

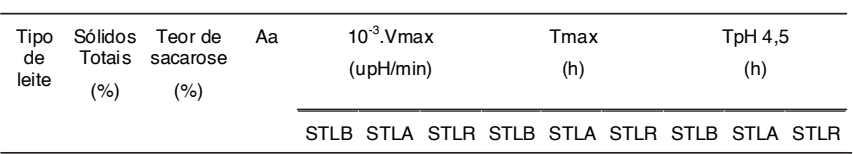

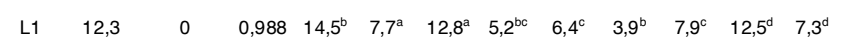

$$
\begin{aligned}
& \begin{array}{lllllllllllll}
\text { L2 } & 19,5 & 8 & 0,985 & 19,0^{\mathrm{c}} & 12,8^{\mathrm{b}} & 15,2^{\mathrm{d}} & 4,7^{\mathrm{b}} & 3,8^{\mathrm{a}} & 2,6^{\mathrm{a}} & 6,6^{\mathrm{a}} & 8,2^{\mathrm{a}} & 5,5^{\mathrm{a}}
\end{array} \\
& \text { L3 } \quad \begin{array}{llllllllllll}
14,7 & 0 & 0,987 & 12,9^{\mathrm{a}} & 11,7^{\mathrm{b}} & 13,7^{\mathrm{b}} & 4,4^{\mathrm{b}} & 4,3^{\mathrm{b}} & 3,0^{\mathrm{a}} & 7,1^{\mathrm{a}} & 10,2^{\mathrm{c}} & 6,8^{\mathrm{c}}
\end{array}
\end{aligned}
$$

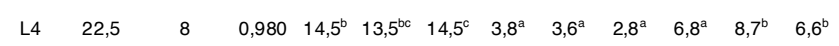

O tempo para atingir $\mathrm{pH} 4,5, \mathrm{pH}$ de parada da fermentação, variou de 5,5h (L2, STLR) a 12,5h (L1, STLA). Observa-se pela Tabela 1, o efeito do aumento do teor de sólidos e da concentração de sacarose sobre TpH4,5. Usando-se a co-cultura STLB, não houve efeito significativo $(\mathrm{p} \leq 0,05)$ com aumento do teor de sólidos e adição de sacarose. A adição de sacarose e a padronização do leite afeta significativamente $\mathrm{TpH} 4,5$ quando se emprega STLA. O TpH4,5 é sensivelmente reduzido quando da utilização de sacarose (cerca de 40\%). Para a cocultura STLR, existe diferença significativa entre TpH4,5 dos leites L2, L3 e L4.

\section{2 - Pós-acidificação}

O valor de $\mathrm{pH}$ dos leites fermentados variou de 4,12 a 4,55 e de 4,03 a 4,43 após 1 e 7 dias de armazenamento a $4^{\circ} \mathrm{C}$, respectivamente. Após $1 \mathrm{dia}$, o menor valor de
$\mathrm{pH}$ foi obtido em leite fermentado pelas bactérias do iogurte (STLB) independente do tipo de leite empregado. O pH dos leites fermentados por STLB, STLR e STLA foi significativamente crescente, nesta ordem, quando foi empregado leite padronizado ou não sem sacarose. Em leites contendo sacarose, os menores valores de $\mathrm{pH}$ foram obtidos com STLB enquanto não foram observadas diferenças significativas para os leites fermentados por STLR e STLA (Figura 1a). Após 7 dias de armazenamento, os valores de $\mathrm{pH}$ dos leites fermentados por STLA mostraram pós-acidificação mais acentuada, sendo inferiores aos $\mathrm{pH}$ daqueles fermentados por STLB $(\mathrm{p} \leq 0,05)$. Os leites fermentados por STLR mostraramse mais estáveis quanto à pós-acidificação (Figura 1b).

Após 1 dia, a acidez total dos leites fermentados foi de 70,18 a $108,78^{\circ} \mathrm{D}$. Os leites com teor de sólidos de $12 \%$ adicionados ou não de sacarose apresentaram menor acidez total, independente da co-cultura empregada, com exceção para STLA. Os leites contendo maiores teores de sólidos totais foram aqueles com maior acidez total, independente da co-cultura usada. Após 7 dias a acidez total aumentou ficando entre 75,19 a $111,91^{\circ} \mathrm{D}$. A menor acidez total foi obtida com os leites contendo $12 \%$ de sólidos totais e, a maior, com aqueles com $15 \%$ de sólidos totais $(\mathrm{p} \leq 0,05)$.

\section{3 - Firmeza de leites fermentados}

Após um dia de armazenamento, o leite fermentado com STLB apresentou maior firmeza (31,5 a 41,5g) segundo o leite utilizado. Empregando-se a co-cultura STLR, obteve-se a menor firmeza (13,9 a 20,9g) enquanto com STLA esta variou de 10,9 a 30,0g (Figura 2a). Estes valores foram inferiores aos determinados por OLIVEIRA et al. [11] que enriqueceram o leite com proteinas de leite e hidrolisado de caseína e empregando as culturas ST7, LA5 e LC35 também em co-cultura.
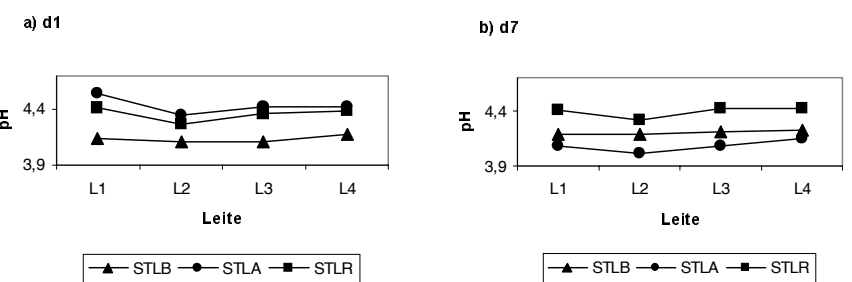

FIGURA 1. Pós-acidificação de leites fermentados preparados com bactérias do iogurte $S$. thermophilus e L. bulgaricus (STLB) e probióticas S. thermophilus e L. acidophilus e (STLA) e S. thermophilus e L. rhamnosus (STLR) em diferentes tipos de leites (L1: leite + 0\% de sacarose; L2: leite + $8 \%$ de sacarose; L3: leite $15 \%$ sólidos totais $+0 \%$ de sacarose; L4: leite 15\% sólidos totais $+8 \%$ de sacarose) após 1 (a) e 7 (b) dias de armazenamento a $4^{\circ} \mathrm{C}$.

Após 7 dias de armazenamento, a firmeza dos leites fermentados permaneceu praticamente estável, com exceção daquele preparado com STLA, que aumentou cerca de $9 \%$ em média. Usando-se leite adicionado de $8 \%$ de sacarose obteve-se a maior firmeza, enquanto não foram observadas diferenças significativas quando 
empregou-se os demais tipos de leite $(\mathrm{p} \leq 0,05)$ (Figura $2 b)$. A menor firmeza foi obtida usando-se STLR em leite. Com o aumento do teor de sacarose e de sólidos solúveis houve um aumento da firmeza usando-se as co-culturas STLR e STLA.
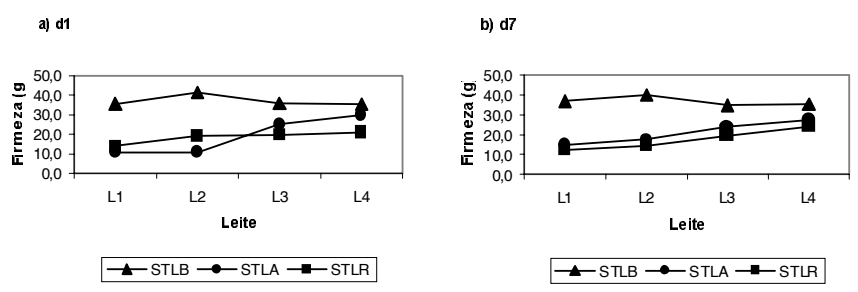

FIGURA 2. Firmeza de leites fermentados preparados com bactérias do iogurte $S$. thermophilus e L. bulgaricus (STLB) e probióticas S. thermophilus e L. acidophilus e (STLA) e S. thermophilus e L. rhamnosus (STLR) em diferentes tipos de leites (L1: leite $+0 \%$ de sacarose; L2: leite $+8 \%$ de sacarose; L3: leite $15 \%$ sólidos totais $+0 \%$ de sacarose; L4: leite $15 \%$ sólidos totais $+8 \%$ de sacarose) após 1 (a) e 7 (b) dias de armazenamento a $4^{\circ} \mathrm{C}$.

Observou-se efeito significativo da adição de sacarose e do aumento do teor de sólidos totais do leite, bem como da co-cultura empregada na firmeza dos leites fermentados $(p \leq 0,05)$.

\section{4 - Viabilidade das culturas}

A viabilidade de S. thermophilus, L. bulgaricus, L. acidophilus e L.rhamnosus pode ser vista na Figura 3.

O número de $S$. thermophilus médio foi de $3,7 \times 10^{9}$ $\mathrm{UFC} / \mathrm{mL}$ e $6,2 \times 10^{9} \mathrm{UFC} / \mathrm{mL}$ após 1 e 7 dias de armazenamento, respectivamente, predominando sobre o número de bactérias do iogurte e probióticas (Figura 3a). Segundo DAVE \& SHAH [3] e VINDEROLA \& REINHEIMER [23] para culturas mistas de $S$. thermophilus e $L$. acidophilus o primeiro predomina sob todas as condições de culturas usadas.
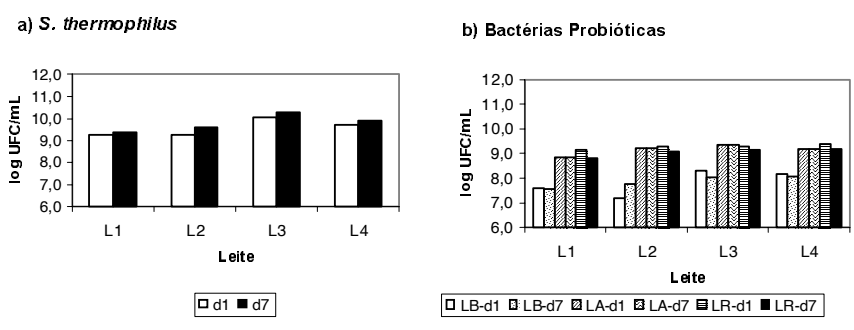

FIGURA 3. Viabilidade de $S$. thermophilus e L. bulgaricus (LB) e das probióticas L. acidophilus (LA) e L. rhamnosus (LR) em 4 diferentes tipos de leite (L1, L2, L3 e L4) fermentados após 1 (d1) e 7 (d7) dias de armazenamento a $4^{\circ} \mathrm{C}$.

Observa-se que após 1 dia de armazenamento obteve-se, em média, 6,5x10 ${ }^{7} \mathrm{UFC} / \mathrm{mL}, 1,4 \times 10^{9} \mathrm{UFC} /$ $\mathrm{mL}$ e $1,8 \times 10^{9} \mathrm{UFC} / \mathrm{mL}$ de L. bulgaricus, L. acidophilus e L. rhamnosus, respectivamente. Após 7 dias, o número de bactéria probiótica média manteve-se estável, enquanto de $L$. bulgaricus apresentou um ligeiro aumento
(Figura 3b). L. rhamonosus apresentou melhor viabilidade, como anteriormente verificado por NIGHSWONGER, BRASHEARS \& GILLILAND [9] e OLIVEIRA et al. [11]. Em todos os casos, a população foi superior ao sugerido pela literatura $[14,23]$.

\section{4 - CONCLUSÕES}

A adição de sacarose e a padronização do leite afetam significativamente o tempo para atingir $\mathrm{pH} 4,5(\mathrm{TpH} 4,5)$ dos leites fermentados pelas co-culturas Streptococcus thermophilus e Lactobacillus acidophilus; Streptococcus thermophilus e Lactobacillus rhamnosus. Os leites fermentados por Streptococcus thermophilus e Lactobacillus acidophilus mostraram pós-acidificação mais acentuada após 7 dias de armazenamento. Observou-se aumento da firmeza com o aumento do teor de sacarose e de sólidos solúveis usando-se as co-culturas Streptococcus thermophilus e Lactobacillus acidophilus ; Streptococcus thermophilus e Lactobacillus rhamnosus. O número de bactérias probióticas foi superior ao sugerido pela literatura e se manteve estável após 7 dias de armazenamento. O número de Streptococcus thermophilus predominou sobre as demais culturas em todas as condições estudadas.

\section{5 - REFERÊNCIAS BIBLIOGRÁFICAS}

[1] BÉAL, C.; DESCHAMPS, N.; JUILLARD, V.; ROISSART, H.; RICHRAD, J.; SARAUX, B. Cinétiques de croissance et d'aciditification des bactéries lactiques. In: Roissart, H., Luquet, F.M., eds. Bactéries Lactiques, Lorica: Chemin de Saint Georges, v. 1, p. 367-401, 1994.

[2] CORRIEU, G.; SPINNLER, H.E.; PICQUE, D.; JOMIER, Y. 1988. Procédé de mise en évidence et de contrôle de l'activité acidifiante d'agents de fermentation dans des bains de fermentation et dispositif pour sa mise en œuvre. Institut National de la Recherche Agronomique, French Pat. Num. 8814456.

[3] DAVE, R.I.; SHAH, N.P. Ingredient supplementation effects on viability of probiotic bacteria in yoghurt. J. Dairy Science, v. 81, p. 2804-2816, 1998.

[4] DAVE, R.I.; SHAH, N.P. Viability of yoghurt and probiotic bacteria in yoghurts made from commercial starters cultures. Int. Dairy J., v. 7, p. 31-41, 1997.

[5] GARDINI, F.; LANCIOTTI, R.; GUERZONI, M.E.; TORRIANI, S. Evaluation of aroma production and survival of Streptococcus thermophilus, Lactobacillus delbrueckii subsp. bulgaricus and Lactobacillus acidophilus in fermented milks. Int. Dairy J., v. 9, p. 125-134, 1999.

[6] INSTITUTO ADOLFO LUTZ. Normas analíticas do Instituto Adolfo Lutz. São Paulo: IAL, v.1, 371p., 1976.

[7] KLAVER, F.A.M.; KINGMAN, F.; WEERKAMP, A.H. Growth and survival of bifidobacteria in milk. Netherland Milk Dairy J., v. 47, p. 151-164. 1993.

[8] MOREIRA, M.; ABRAHAM, A.; De ANTONI, G. Technological properties of milks fermented with thermophilic lactic acid bacteria at suboptimal temperature. J. Dairy Sci., v. 83, p. 395-400, 2000.

[9] NIGHSWONGER, B.D.; BRASHEARS, M.M.; GILLILAND, S.E. Viability of Lactobacillus acidophilus and Lactobacillus casei in fermented milk products during refrigerated storage. J. Dairy Sci., v. 79, p. 212-219, 1996. 
[10] O`NEIL, J.M.; KLEYN, D.H.; HARE, L.B. Consistency and compositional characteristics of commercial yoghurts. J. Dairy Sci., v. 62, p. 1032-1036, 1979.

[11] OLIVEIRA, M.N.; SODINI, I.; REMEUF, F.; CORRIEU, G. Effect of milk supplementation and culture composition on acidification, textural properties and microbiological stability of fermented milks containing probiotic bacteria. Intern Dairy J., v. 11, n. 11-12, p. 935-942, 2001.

[12] PONS, M.; FISZMAN, S.M. Instrumental texture profile analysis with particular reference to gelled systems. J. Text Stud., v. 27, p. 597-624, 1996.

[13] ROSSI, E.A. Formulação de um sucedâneo do iogurte a base de soro de leite e extrato aquoso de soja. Londrina, 1983. Dissertação de Mestrado-Universidade Estadual de Londrina.

[14] RYBKA, S.; FLEET, G.H. Populations of Lactobacillus delbrueckii ssp bulgaricus, Streptococcus thermophilus and Bifidobacterium species in Australian yoghurts. Food Australia, v. 49, p. 471-475, 1997.

[15] SAMONA, A.; ROBINSON, R.K. Effect of yogurt culture on the survival of bifidobacteria in fermented milks. J. of the Society of Dairy Technol, v. 42, n. 2, p. 58$60,1994$.

[16] SANDERS, M.E. Probiotics. Food Technol., v. 53, p. 67-77, 1999.

[17] SHAH, N.P. Probiotic bacteria: selective enumeration and survival in dairy foods. J. Dairy Sci., v. 83, n. 4, p. 894-907, 2000.
[18] SHAH, N.P.; LANKAPUTHRA, W.E.V. Improving viability of Lactobacillus acidophilus and Bifidobacterium spp. in yogurt. Int. Dairy J., v. 7, p. 349-356, 1997.

[19] SHAH, N.P.; ALI, J.F.; RAVULA, R.R. Populations of Lactobabillus acidophilus, Bifidobacterium spp., and Lactobacillus casei in commercial fermented milk products. Biosci Microflora, v. 19, n. 1, p. 35-39, 2000.

[20] SHAH, N.P.; RAVULA, R.R. Influence of water activity on fermentation, organic acids production and viability of yogurt and probiotic bacteria. The Australian J. Dairy Technol., v. 55, n. 3, p. 127-131, 2000.

[21] TRAMER, J. Yogurt cultures. J. Soc. Dairy Technol., v. 26, p. 16-21, 1973.

[22] VANDERHOOF, J.A.; YOUNG, R.J. Use of probiotics in childhood gastrointestinal disorders. J. Pediatric Gastroenterology and Nutrition. v. 27, n. 3, p. 323332, 1998.

[23] VINDEROLA, C.G.; REINHEIMER, J.A. Enumeration of Lactobacillus casei in the presence of Lactobacillus acidophilus and lactic starter in fermented dairy products. Int. Dairy J., v. 10, p. 271-275, 2000.

[24] ZOURARI, A.; ACCOLAS, J.P.; DESMAZEAUD, M.J. Metabolism and biochemical characteristics of yogurt bacteria. Le lait, v. 72, p. 1-34, 1992.

\section{6 - AGRADECIMENTOS}

Os autores agradecem à FAPESP, ao CNPq e à CAPES pelo apoio financeiro e à Rhodia Brasil pelas culturas. 